\title{
Gliding Motility and Expression of Motility-Related Genes in Spreading and Non-spreading Colonies of Flavobacterium columnare
}

OPEN ACCESS

Edited by:

Shicheng Chen,

Michigan State University,

United States

Reviewed by:

Mark J. McBride,

University of Wisconsin-Milwaukee,

United States

Eric Joseph Pollitt,

University of Sheffield,

United Kingdom

Jie Wang,

Michigan State University,

United States

*Correspondence:

Reetta Penttinen

reetta.k.penttinen@jyu.fi

Specialty section:

This article was submitted to Microbial Physiology and Metabolism,

a section of the journal

Frontiers in Microbiology

Received: 08 June 2017 Accepted: 08 March 2018

Published: 26 March 2018

Citation:

Penttinen R, Hoikkala $V$ and Sundberg L-R (2018) Gliding Motility and Expression of Motility-Related

Genes in Spreading

and Non-spreading Colonies

of Flavobacterium columnare.

Front. Microbiol. 9:525.

doi: 10.3389/fmicb.2018.00525

\section{Reetta Penttinen*, Ville Hoikkala and Lotta-Riina Sundberg \\ Centre of Excellence in Biological Interactions, Department of Biological and Environmental Science and Nanoscience Center, University of Jyväskylä, Jyväskylä, Finland}

Gliding motility facilitates the movement of bacteria along surfaces in many Bacteroidetes species and results in spreading colonies. The adhesins required for the gliding are secreted through a gliding motility-associated protein secretion system, known as the type IX secretion system (T9SS). The fish pathogen Flavobacterium columnare produces spreading (rhizoid $[\mathrm{Rz}]$, soft $[\mathrm{S}]$ ) and non-spreading (rough $[\mathrm{R}]$ ) colony types, of which only the spreading Rz type is virulent. In this study, we explored the spreading behavior of these colony types by microscopic imaging and measured the expression of genes associated with gliding motility and T9SS (g/dG, gldH, g/dL, sprA, sprB, sprE, sprF, sprT, and porV) under high and low resource levels by using RTqPCR (reverse transcription quantitative PCR). The spreading colony types responded to the low resource level with increased colony size. The non-spreading colony type, as well as the cells growing under high nutrient level expressed only moderate cell movements. Yet, a low nutrient level provoked more active gliding motility in individual cells and increased spreading by cooperative gliding. The gene expression survey demonstrated an increased expression level of sprA (a core component of T9SS) and sprF (needed for adhesin secretion) under low nutrient conditions. Surprisingly, the expression of gliding motility genes was not consistently associated with more active spreading behavior. Furthermore, no genetic differences were found between spreading and non-spreading colony types in the studied genes associated with gliding motility. Our study demonstrates that environmental nutrient level is an important regulator of both gliding motility and the expression of some of the associated genes. These results may help to understand the connections between nutrient concentration, gliding motility, and virulence of $F$. columnare.

Keywords: colony type, Flavobacterium columnare, gene expression, gliding motility, nutrients, RT-qPCR, T9SS, type IX secretion system

\section{INTRODUCTION}

Gliding motility is a process of bacterial movement on surfaces exploited by several bacterial species in the phylum Bacteroidetes (McBride and Zhu, 2013). Instead of involving flagellae or pili, gliding motility is enabled by complex machinery that has been studied more closely in Flavobacterium johnsoniae (for a review of Flavobacterium gliding motility, see McBride and Nakane, 2015), a 
model system for gliding motility. Number of studies of flavobacterial gliding motility have led to the identification of several genes involved in motility, including gld $A$, gldB, gldD, gldF, gldG, gldH, gldI, gldJ, gldK, gldL, gldM, gldN, sprA, sprB, sprE, and sprT (Agarwal et al., 1997; Hunnicutt and McBride, 2000, 2001; Hunnicutt et al., 2002; McBride et al., 2003; McBride and Braun, 2004; Braun and McBride, 2005; Nelson et al., 2007, 2008; Sato et al., 2010; Rhodes et al., 2010, 2011b; Kharade and McBride, 2015). Furthermore, a subset of these genes, gldK, gldL, gldM, gldN, sprA, sprE, and sprT, has been found to compose a protein translocation system, designated the type IX secretion system (T9SS) (Sato et al., 2010; McBride and Zhu, 2013). T9SS-related genes are restricted to Bacteroidetes, with no prevalent similarity between the previously described secretion systems (McBride and Zhu, 2013). T9SS has an important role in the secretion of gliding motility adhesins, being required both for surface contact and for secretion of virulence factors (Sato et al., 2010; Shoji et al., 2011). For example, the periodontal pathogen Porphyromonas gingivalis uses T9SS for secretion of its major virulence factors, which are gingipains and hemagglutinins (Sato et al., 2010; Shoji et al., 2011).

The exact role of each component in the gliding motility machinery of $F$. johnsoniae is not yet fully understood. GldB, GldD, GldH, GldI, and GldJ are lipoproteins needed for gliding, but their exact functions are not known (Hunnicutt and McBride, 2000, 2001; McBride et al., 2003; McBride and Braun, 2004; Braun and McBride, 2005). GldA, GldF, and GldG form an $\mathrm{ABC}$ transporter but its role in gliding is still largely unknown (Agarwal et al., 1997; Hunnicutt et al., 2002). sprB is a motility adhesin needed for gliding, and it is secreted via the T9SS (Sato et al., 2010). The SprB encoding gene is located in operon $\operatorname{sprCDBF}$, where it is transcribed together with $s p r C$ and $s p r D$, genes coding for proteins that support SprB function, and with sprF, which is needed for successful secretion of SprB (Rhodes et al., 2011a). In addition, a recently identified gene, $\operatorname{por} V$, is needed for secretion of chitinase and adhesin RemA in F. johnsoniae (Kharade and McBride, 2015). The mechanisms that control the assembly and activity of gliding motility machinery and T9SS are not known. In P. gingivalis, a two-component regulative system consisting of PorX and PorY regulates the expression of a subset of T9SS genes (Sato et al., 2010).

Flavobacterium columnare is a fish pathogen belonging to the phylum Bacteroidetes. F. columnare carries the majority of the orthologous genes (Tekedar et al., 2012) involved in flavobacterial gliding motility and T9SS, which are used for virulence factor secretion and formation of spreading colonies (Sato et al., 2010; McBride and Nakane, 2015). F. columnare can form different colony morphotypes, including the spreading rhizoid (Rz) and soft (S) colony types as well as the nonspreading rough (R) type (Kunttu et al., 2009; Laanto et al., 2012). Spreading colony morphology has been suggested to be essential for F. columnare virulence (Kunttu et al., 2009; Laanto et al., 2012), and indeed, only the spreading Rz type is virulent in the fish host (Kunttu et al., 2009; Laanto et al., 2012, 2014). Furthermore, changes in nutrient concentration in agar culture changes spreading behavior of F. columnare colonies, especially in the virulent $\mathrm{Rz}$ type (Laanto et al., 2012). Nutrient availability also has a significant impact on virulence in F. columnare as a high nutrient level induces higher virulence in the bacteria (Penttinen et al., 2016; Kinnula et al., 2017). The functionality of gliding motility and T9SS in different $F$. columnare morphotypes is not known, although gldL, gldM, gldN, and gldH have been suggested as putative virulence-associated factors in F. columnare (Dumpala et al., 2010; Klesius et al., 2010). Indeed, a recent paper by Li et al. (2017) shows decreased virulence in a secretiondeficient T9SS mutant. Furthermore, a transcriptome-wide study of F. columnare strain ATCC 49512 demonstrated that genes associated with gliding motility and spreading are located in actively transcribed operons (Tekedar et al., 2017). Yet, there is a significant gap in the current understanding of the genetic factors underlying the virulent and non-virulent colony morphologies. In addition, how the environmental conditions regulate the gliding motility and expression of the T9SS in F. columnare has remained poorly understood. These issues have to be clarified in order to understand pathogenesis of F. columnare.

Here, we explored gliding motility in $F$. columnare spreading $(\mathrm{Rz}, \mathrm{S})$ and non-spreading $(\mathrm{R})$ morphotypes under conditions that were expected to induce (low-nutrient) or reduce (highnutrient) spreading behavior. Gliding motility and individual cell movements were seen to be more active under low-nutrient conditions. We also performed a RT-qPCR assay in order to measure the gene expression of T9SS or gliding motility -associated genes gldG, gldH, gldL, sprA, sprB, sprE, sprF, sprT, and porV. Of these genes, gldL, porV, sprA, sprE, and $s p r T$ are associated with the T9SS. Increased gene expression in response to low nutrient availability was detected in $s p r A$ and $s p r F$. However, the spreading and non-spreading colony types had different expression profiles under different resource levels, which could be an indication of divergent metabolic programs.

\section{RESULTS}

\section{Nutrient Availability Regulates Colony Spreading in $\mathbf{R z}$ and S Morphotypes}

The morphology of bacterial colonies was assayed on $0.5 \mathrm{xN}$, $1 \mathrm{x}$ and $2 \mathrm{xN}$ Shieh plates, as these nutrient levels have previously been shown to be useful for exemplifying gliding motility in F. columnare (Laanto et al., 2012). The bacteria originating from the same liquid culture were spread on agar plates and grown for 2 days after which the colony morphology was imaged under a light microscope (Figure 1). $\mathrm{Rz}$ colonies grown on a $0.5 \mathrm{xN}$ Shieh plate were spreading with increased mean colony size $(3.95 \mathrm{~mm}, \mathrm{SE} \pm 0.42)$ and the production of root-like protrusions typical for $\mathrm{Rz}$ morphology (Figures 1, 2A). Rz colonies grown on $2 \mathrm{xN}$ Shieh plates had a smaller mean colony size $(0.73 \mathrm{~mm}, \mathrm{SE} \pm 0.04)$, and rootlike structures, if seen, were only moderate (Figures 1, 2A). Type $S$ responded to changing nutrient availability comparably to $\mathrm{Rz}$ (mean colony size $2.4 \mathrm{~mm}$, SE \pm 0.23 in $0.5 \mathrm{xN}$ and $0.75 \mathrm{~mm}$, SE \pm 0.06 in $2 \mathrm{xN})$. However, when grown at lower nutrient conditions $(0.5 \mathrm{xN}$ Shieh), root-like structures were also observed in the $\mathrm{S}$ type. These colonies were, 


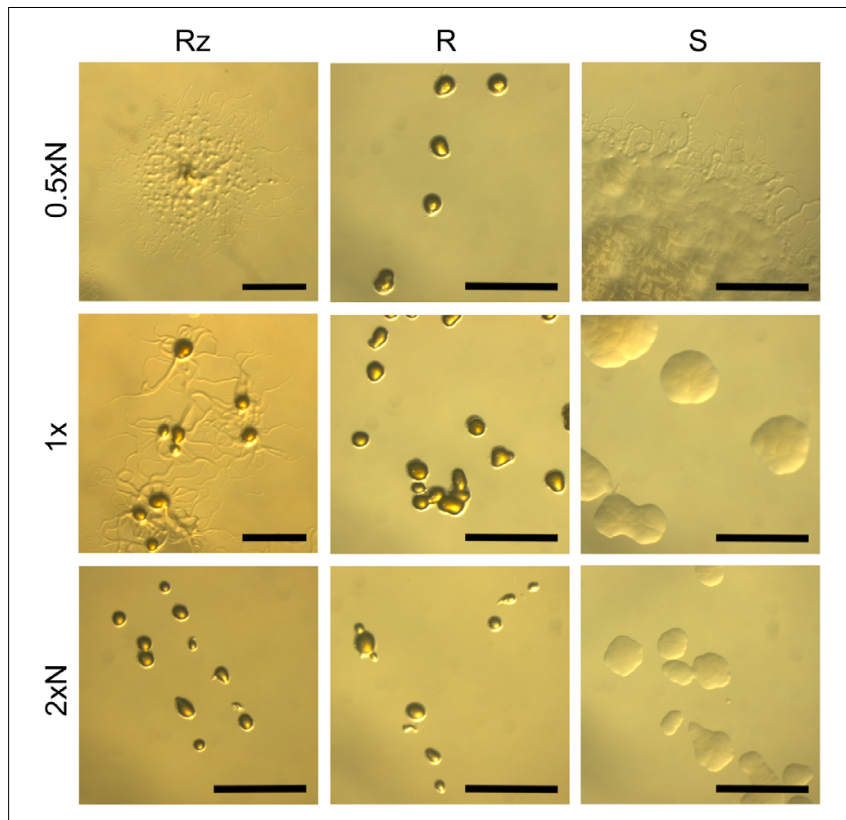

FIGURE 1 | F. columnare B067 colony types $\mathrm{Rz}, \mathrm{R}$, and $\mathrm{S}$ growing on $0.5 \mathrm{xN}$, $1 \mathrm{x}$, and $2 \mathrm{xN}$ Shieh agar plates. $\mathrm{N}$ refers to peptone and yeast extract concentrations which were either halved $(0.5 x N)$, normal $(1 \mathrm{x})$, or doubled $(2 \times N)$. See Figure 2A for the mean colony sizes. Scale bars $1 \mathrm{~mm}$.

nevertheless, distinguishable from $\mathrm{Rz}$ colonies by their nonadherent, opaque, and moist appearance (Figure 1). R type did not remarkably alter the colony size in response to changing nutrient availability (mean colony size $0.7 \mathrm{~mm}, \mathrm{SE} \pm 0.03$ in $0.5 \mathrm{xN}$ and $0.5 \mathrm{~mm}, \mathrm{SE} \pm 0.00$ in $2 \mathrm{xN}$ ) and root-like structures were only occasionally seen under low nutrient conditions (Figures 1, 2A).

\section{Growth and Biofilm Formation in Varying Nutrient Concentrations}

The viability of $\mathrm{Rz}, \mathrm{R}$, and $\mathrm{S}$ colony types in $0.5 \mathrm{xN}$ and $2 \mathrm{xN}$ Shieh media was measured as the maximum optical density $\left(\mathrm{OD}_{\max }\right)$ reached during a 65 -h cultivation period (Figure 2B). All colony types reached the highest $\mathrm{OD}_{\max }$ at higher nutrient level $(2 \mathrm{xN}$ Shieh). The biofilm forming ability was remarkably higher under low nutrient conditions $(0.5 \mathrm{xN}$ Shieh $)$ in the $\mathrm{Rz}$ type compared to $2 \mathrm{xN}$ Shieh as well as to the $\mathrm{R}$ and $\mathrm{S}$ types, which were weaker biofilm producers at both nutrient levels (Figure 2C).

\section{Imaging of Bacterial Movements}

The movements of individual $\mathrm{Rz}$ cells grown on $0.5 \mathrm{xN}$ and $2 \mathrm{xN}$ Shieh agar plates were recorded with a confocal microscope. The movements of $\mathrm{Rz}$ cells were comparable with the previously described gliding motility of F. johnsoniae; the cells glided over the surface in a straightforward manner, occasionally attaching to the surface with one end of the cell, rotating, and changing the moving direction (Supplementary Videos 1,2). The gliding speed was slower than that seen in F. johnsoniae, which was used as a reference (data not shown).
The movements of individual bacteria growing as a part of forming biofilm were recorded between the agar layer and microslide chamber bottom. The colony types $\mathrm{Rz}$ and $S$ formed a monolayer on the edges of spreading bacterial biofilm, where the cells were organized side by side and glided along the adjacent cells (Figure 3 and Supplementary Videos $3,4,7,8)$. The cells formed branching rhizoid-like structures a few cells wide (here referred to as microrhizoids), which involved both motile and non-motile cells. In both $\mathrm{Rz}$ and $S$ types, more active gliding motility was seen under low nutrient concentrations $(0.5 \mathrm{xN})$. Colony type $\mathrm{R}$ expressed only occasional movements regardless of the nutrient level, and cellular organization as a spreading biofilm was not observed (Supplementary Videos 5, 6). In order to visualize F. columnare colony formation on a longer timescale, the growth of the $\mathrm{Rz}$ colony type on $1 \mathrm{x}$ Shieh was recorded over the course of $8 \mathrm{~h}$ (Supplementary Video 9). In the front of the biofilm, the bacteria were characteristically organized in microrhizoids, which moved cooperatively toward the spreading direction of the biofilm and seemed also to serve as routes along which other cells were able to glide further and support biofilm expansion.

\section{Sequence Analysis and Expression of Gliding Motility-Associated Genes}

Genes putatively involved in gliding motility were sequenced from $\mathrm{Rz}, \mathrm{R}$, and $\mathrm{S}$ types of strain F. columnare B067. No genetic differences were detected between the colony types in the gene sequences of operons gldFG and gldKLMN, genes gld $H$, sprA, sprC, sprD, sprE, sprF, sprT, porV, porX, and porY, or in the predicted regulative regions upstream from the genes gldH, sprA, sprE, and porV or operons gldFG, gldKLMN, and sprCDBF. Expression of genes gldG, gld H, gldL, sprA, sprB, sprE, sprF, sprT, and porV, which are putatively involved in F. columnare gliding motility, was measured in B067 Rz, R, and $S$ colony types that had been grown on $0.5 x$ and $2 x$ Shieh agar plates. Of these genes, gldL, sprA, sprE, sprT, and por $V$ are associated with the T9SS. Gene expression results were normalized with reference genes gapdh and $g l y A$, which are stably expressed in the current dataset (the $M$ value was 0.5834 for both genes, with a variance coefficient of 0.2114 for gapdh and 0.2007 for $g l y A$ ). Relative expressions are presented in Figure 4 (for statistics, see Tables 1, 2). Significant differences between colony types were observed in the expression of genes gldG, gldH, gldL, and sprE (Table 1 and Figure 4; for pairwise comparisons, see Table 2). Nutrient levels had a significant effect on gldL, sprA, sprB, and $s p r F$ expression. The pairwise comparisons revealed that $\operatorname{spr} A$ was expressed at significantly higher levels in low-nutrient conditions in $\mathrm{Rz}$ and $\mathrm{R}$ types, and the same pattern was detected in $s p r F$ expression in the $\mathrm{R}$ type (Table 2 and Figure 4). However, significant interaction between the colony type and nutrient was detected in $g l d H$, gldL, sprA, and sprE (Table 1), indicating that gene expression of colony types may differ between nutrient conditions. Indeed, direct associations between spreading behavior and gliding motility gene expression were challenging to form as different colony types seemed to respond differently to the 
A

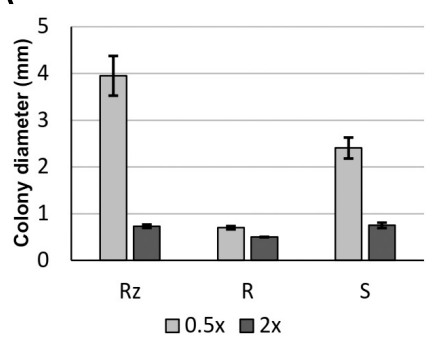

B

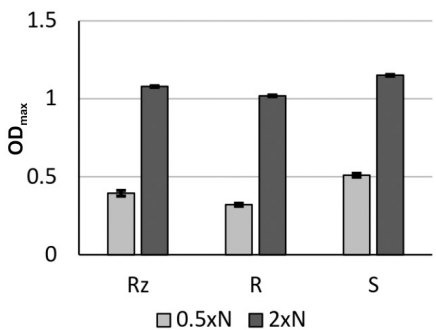

C

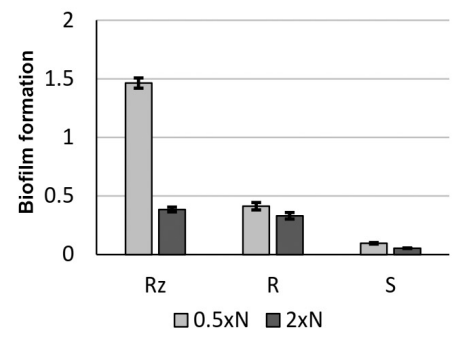

FIGURE 2 | Growth characteristics of $F$. columnare B067 colony types Rz, R, and S in different nutrient levels. Mean colony size in millimeters ( \pm SE) of colonies growing on $0.5 x$ and $2 x$ Shieh agar plates (A). Maximum optical density (at $600 \mathrm{~nm})( \pm \mathrm{SE}$ ) reached during a 65-h-liquid cultivation in 0.5xN and 2xN Shieh (B). Biofilm formation (at $595 \mathrm{~nm}$ ) ( \pm SE) after $44 \mathrm{~h}$ in $0.5 \times \mathrm{N}$ and $2 \times \mathrm{N}$ Shieh (C).

nutrient level with motility gene expression. Even though a significant effect of colony type was not observed in either $\operatorname{spr} T$ or por $V$, a significant difference between $\mathrm{Rz}$ and $\mathrm{R}$ was observed in $\operatorname{spr} T$ and between $\mathrm{Rz}$ and $\mathrm{S}$ in por $\mathrm{V}$ expression (Table 2).

\section{Proteolytic Activity and Extracellular Secretion in Different Nutrient Concentrations}

Colony types $\mathrm{Rz}, \mathrm{R}$, and $\mathrm{S}$ were cultivated on $0.5 \mathrm{xN}$ and $2 \mathrm{xN}$ Shieh plates containing $1.5 \%$ skim milk. Proteolytic activity was observed in each colony variant, seen as the formation of a clear degradation zone peripheral to the bacterial growth, but no differences between the colony types were observed, and the nutrient concentration did not affect the proteolytic activity (Supplementary Figure S1). The effect of colony type and nutrient availability on the contents of extracellularly secreted products (ECPs) was analyzed further. Generally, Rz, R, and $\mathrm{S}$ grown in $0.5 \mathrm{xN}$ and $2 \mathrm{xN}$ liquid Shieh cultures shared a common overall ECP profile, with some moderate changes in individual protein bands between colony types (Supplementary Figure S2). However, a strong protein band, approximately 13 $\mathrm{kD}$ in molecular weight, was detected in $\mathrm{Rz}$ type grown in both $0.5 \mathrm{xN}$ and $2 \mathrm{xN}$ Shieh media. The corresponding band was absent or barely detectable in $\mathrm{R}$ or $\mathrm{S}$ types.

\section{DISCUSSION}

The ability to move toward nutrient sources and the host is essential for the survival of bacteria, and bacterial virulence has been shown to be associated with motility in several bacterial species (e.g., Josenhans and Suerbaum, 2002; McGee et al., 2002; Haiko and Westerlund-Wikstrom, 2013). Comparative genomic analysis has revealed that several members of Bacteroidetes employ a unique gliding motility machinery and a motility-related secretion system T9SS (McBride and Zhu, 2013). Cells possessing a functional gliding motility system characteristically form spreading colonies (McBride and Nakane, 2015). F. columnare and F. psychrophilum are pathogenic in fish, affecting freshwater aquaculture on a global scale
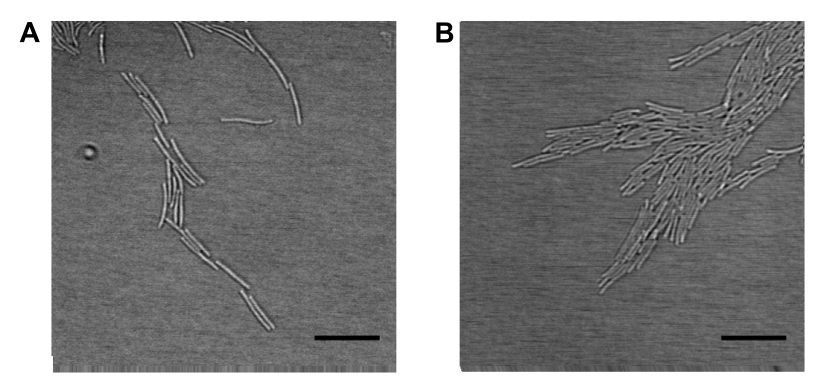

FIGURE 3 | Organization of F. columnare B067 cells as microrhizoids on the edges of biofilm. Rz colony type grown under $1 \times$ Shieh agar layer $(\mathbf{A})$ and $S$ type under 0.5xN Shieh agar (B). Scale bars $10 \mu \mathrm{m}$.

(Wagner et al., 2002; Declercq et al., 2013; Nilsen et al., 2014). It has been suggested that T9SS may have a central role in the pathogenesis of these species (Laanto et al., 2012; Castillo et al., 2015). This was confirmed recently with T9SS-mutant F. columnare, which was demonstrated to have a decreased level of virulence (Li et al., 2017).

Here, we imaged the gliding motility of spreading and nonspreading colonies of $F$. columnare and measured the expression of genes related to gliding and secretion. Colony types $\mathrm{Rz}$ and $S$ responded to decreased nutrient concentration by increasing spreading behavior, but $\mathrm{R}$ type did not have this plastic feature, as reported previously by Laanto et al. (2012). However, mutations were not found in the studied gliding motility genes, indicating that other genes may also be needed for the formation of spreading colonies. Although a decrease in nutrients remarkably increased the spreading of colonies, it did not correspond to the expression of gliding motility genes in a uniform manner. We also found that the capacity for extracellular secretion of proteases was maintained in the non-spreading morphologies, which may denote the presence of functionally intact secretion systems.

Each colony type was viable both at low- and high-nutrient conditions, when they were cultivated in a liquid medium. Even though each colony type was more successful at a high nutrient level (in liquid), they all expressed low colony spreading when they were cultivated on agar plates (under the same nutrient conditions). This finding indicates that smaller colonies are not 

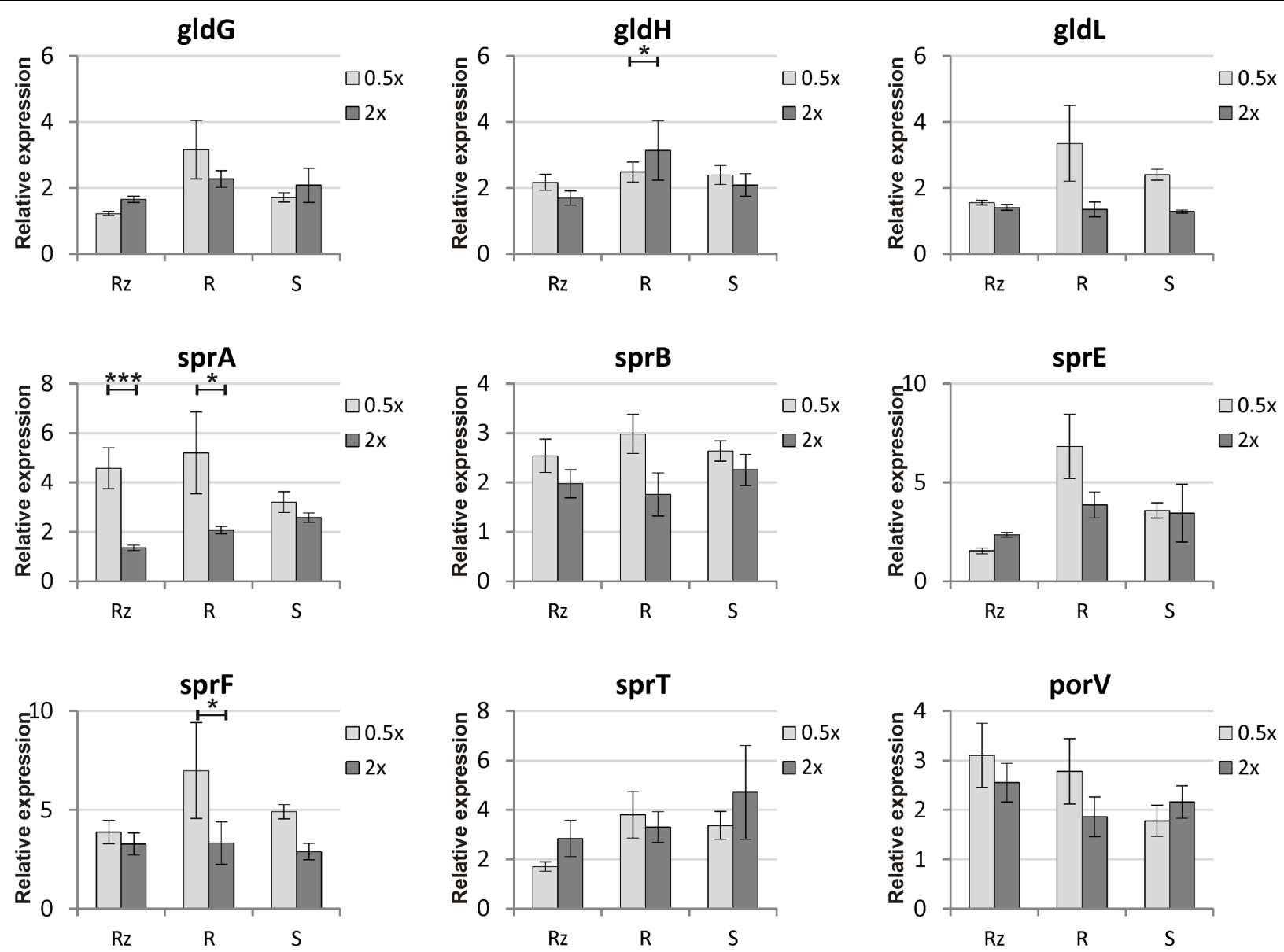

FIGURE 4 | Relative gene expressions of gliding motility and T9SS genes ( \pm SE) in F. columnare B067 colony morphologies Rz, R and S cultivated on 0.5x and 2x Shieh agar plates. The concentration of all Shieh components was either halved (0.5x) or doubled (2x) compared to the normal Shieh medium. For detailed statistical analysis of the gene expression results, see Tables 1, 2. Asterisks indicate the statistical significance ( $p$-values) between treatments: ${ }^{*} p<0.05 ;{ }^{* *} p<0.01$; $* * * p<0.001$.

TABLE 1 | Statistical analysis of gliding motility and T9SS gene expression of $F$. columnare B067 Rz, R and S colony types grown on 0.5x and 2x Shieh agar plates.

\begin{tabular}{|c|c|c|c|c|c|c|c|c|c|}
\hline \multirow[t]{2}{*}{ Gene } & \multicolumn{3}{|c|}{ Colony type } & \multicolumn{3}{|c|}{ Nutrient } & \multicolumn{3}{|c|}{$\begin{array}{c}\text { Colony type* } \\
\text { nutrient interaction }\end{array}$} \\
\hline & $F$ & $d f$ & $p$ & $F$ & $d f$ & $p$ & $F$ & $d f$ & $p$ \\
\hline$s p r B$ & 0.225 & 2 & 0.800 & 6.583 & 1 & 0.016 & 0.185 & 2 & 0.832 \\
\hline$g / d G$ & 10.148 & 2 & $<0.001$ & 0.523 & 1 & 0.476 & 1.289 & 2 & 0.291 \\
\hline gldH & 6.093 & 2 & 0.006 & 0.229 & 1 & 0.636 & 3.918 & 2 & 0.032 \\
\hline porV & 2.268 & 2 & 0.122 & 0.654 & 1 & 0.426 & 0.493 & 2 & 0.616 \\
\hline spra & 0.807 & 2 & 0.456 & 21.363 & 1 & $<0.001$ & 4.433 & 2 & 0.021 \\
\hline sprE & 11.647 & 2 & $<0.001$ & 0.448 & 1 & 0.509 & 3.382 & 2 & 0.048 \\
\hline sprF & 1.681 & 2 & 0.204 & 7.312 & 1 & 0.012 & 1.072 & 2 & 0.356 \\
\hline
\end{tabular}

produced on high-nutrient -agar due to unfavorable growth conditions but rather as a result of reduced cell motility. In biofilm measurements, we found that the $\mathrm{Rz}$ type was the most efficient biofilm producer in the low-nutrient treatment. The $S$ type failed to produce biofilm, although it expressed increased colony spreading under low-nutrient conditions. This indicates that spreading per se is not an indicator of biofilm formation. Biofilm formation is a process in which successful adhesion is 
TABLE 2 | Pairwise comparisons of gliding motility gene expression between F. columnare B067 Rz, R and S colony types and between growth conditions $0.5 x$ and $2 x$ Shieh agar within a colony type.

\begin{tabular}{|c|c|c|c|c|c|c|}
\hline \multirow[t]{2}{*}{ Gene } & \multicolumn{3}{|c|}{ Pairwise comparisons of colony types } & \multicolumn{3}{|c|}{ Nutrient $0.5 x$ vs. $2 x$} \\
\hline & $R z$ vs. $R$ & $R z$ vs. $S$ & $R$ vs. $S$ & $R z$ & $\boldsymbol{R}$ & $S$ \\
\hline sprB & NS & NS & NS & NS & NS & NS \\
\hline gldG & $<0.001$ & NS & 0.004 & NS & NS & NS \\
\hline gldH & 0.002 & NS & 0.009 & NS & 0.028 & NS \\
\hline gldL & 0.0108 & 0.0087 & NS & NP & NP & NP \\
\hline sprT & 0.030 & NS & NS & NS & NS & NS \\
\hline porv & NS & 0.043 & NS & NS & NS & NS \\
\hline sprA & NS & NS & NS & $<0.001$ & 0.019 & NS \\
\hline sprE & $<0.001$ & 0.025 & 0.007 & NS & NS & NS \\
\hline sprF & NS & NS & NS & NS & 0.041 & NS \\
\hline
\end{tabular}

NS: statistically not significant result when confidence level of 0.95 was used; NP: not performed.

TABLE 3 | Primer sequences and properties used in RT-qPCR study of $F$. columnare.

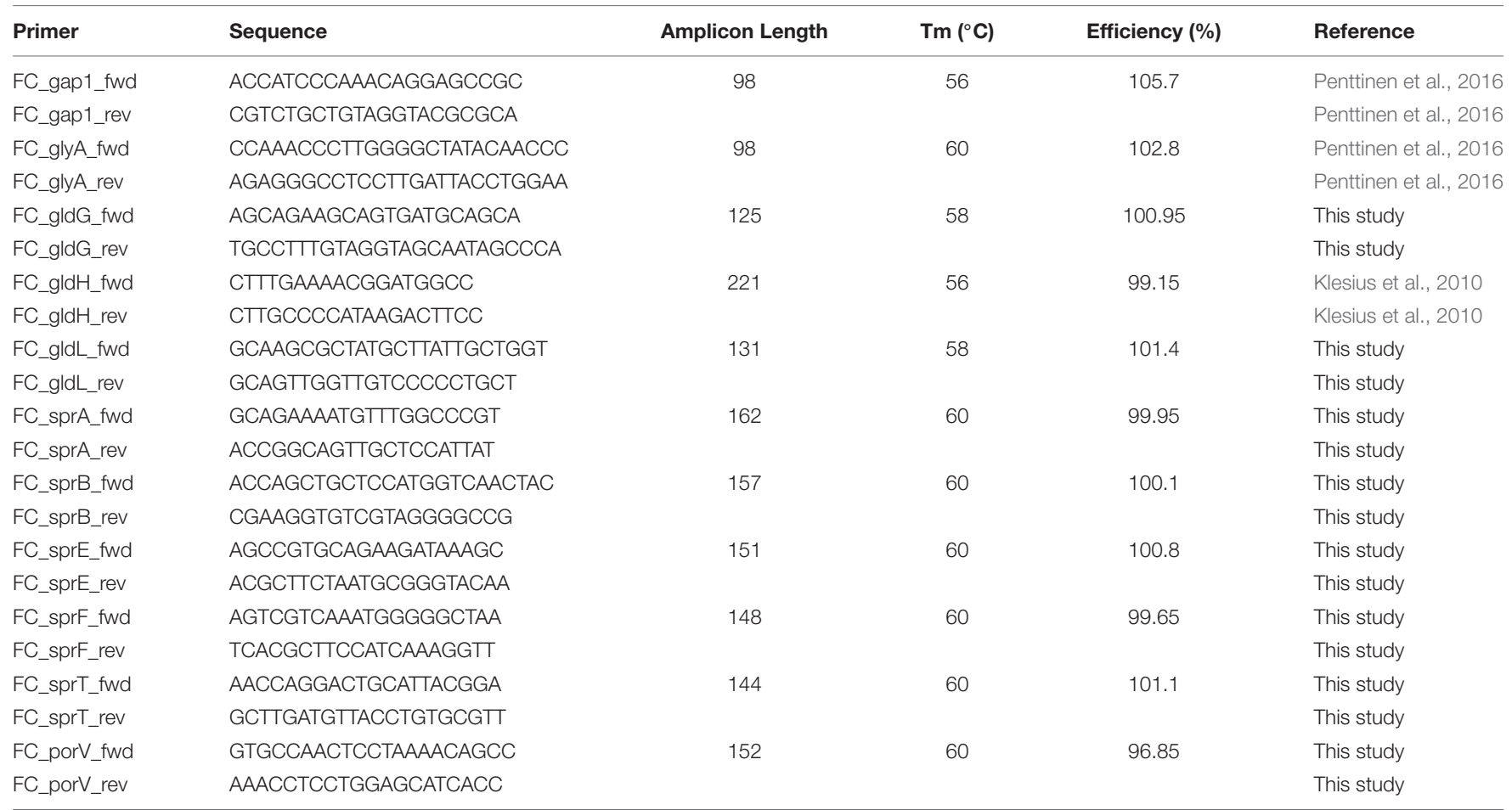

required in order to attach to a surface (Garrett et al., 2008). As the biofilm formation capacity of the $S$ type was comparable to the control (a growth medium without bacteria), it may be incapable of proper surface adhesion, possibly due to lack of functional cell surface adhesins. Indeed, the colonies of the S type are only moderately adherent (Kunttu et al., 2011) and can be removed from agar plates easily compared to the $\mathrm{Rz}$ and $\mathrm{R}$ colony types. However, the capacity for extracellular secretion, gliding, and adhesion to other cells demonstrated in the $S$ colony type indicates that different adhesins are needed for surface adhesion and social motility of $F$. columnare. The adhesins required for $F$. columnare attachment to surfaces of different compositions (abiotic or biotic) are yet to be identified.

Microscopic microrhizoids were observed at the edge of spreading colonies. Importantly, the cells involved in microrhizoids expressed cooperative behavior in terms of social motility as they glided along neighboring cells and, thereby, mediated the spreading of the biofilm. Previously, we have proposed the involvement of social movements in F. columnare biofilm formation due to coordinated cell organization (Laanto et al., 2014). Indeed, bacterial pathogens are known to cooperate, especially with regards to biofilm formation (see e.g., Nadell et al., 2016). Furthermore, high nutrient levels reduced gliding behavior 
in biofilm. We have recently shown that a high environmental nutrient level leads to higher virulence via increased virulence factor expression (Penttinen et al., 2016). Therefore, it remains to be resolved whether motility itself is essential for F. columnare virulence or whether gliding motility and virulence are related solely via a common secretion route for adhesins and virulence factors.

Previous studies in F. johnsoniae have demonstrated that a mutation in any of the gliding motility genes results in disruption of the gliding motility machinery and the formation of nonspreading colonies (see e.g., McBride and Nakane, 2015). In order to study the genetic background of gliding motility in F. columnare spreading and non-spreading colony types, we sequenced genes involved in gliding motility apparatus and T9SS: gldH, sprA, spre, sprF, sprT, and porV and genomic regions spanning gldFG, gldKLMN, and $s p r C D$. Surprisingly, these genes were identical between the spreading $(\mathrm{Rz}$ and $\mathrm{S})$ and the nonspreading $(\mathrm{R})$ colony types. Furthermore, genetic differences were not found in the predicted regulatory regions. A sequence analysis of other gld genes could provide information on differences between the colony types, but it is possible that other genes are also involved in colony spreading. A whole genomesequencing approach of different colony morphotypes would be efficient for identifying genetic factors that contribute to the changes in colony spreading. In $F$. johnsoniae, for example, secDF mutants have been shown to be incapable of gliding motility and chitin utilization and to produce non-spreading colonies (Nelson and McBride, 2006). It was hypothesized that SecDF may not be involved in gliding directly, but may have a role in translocation of GldJ (Nelson and McBride, 2006). Furthermore, transposon mutagenesis revealed that a thiol oxidoreductase-like protein, TlpB, is associated with gliding motility and virulence in F. psychrophilum (Alvarez et al., 2006). Thiol oxidoreductases are essential for the folding of several proteins, including those related to virulence (Fabianek et al., 2000), but their function in F. columnare has not been studied.

We studied the gene expression of gliding motility- or spreading-associated genes in low-nutrient $(0.5 \mathrm{x}$ Shieh $)$ and high-nutrient (2x Shieh) agar plates. Colony spreading increased in low-nutrient conditions and decreased in high-nutrient conditions (Figures 1, 2). Expression of gldG, gldH, gldL, and $\operatorname{sprE}$ (in pairwise comparison, also $\operatorname{spr} T$ and $\operatorname{por} V$, see Tables 1, 2) was significantly influenced by colony type, but the highest expressions were often observed in the non-spreading $\mathrm{R}$ type. In general, gene expression levels were not consistently associated with the activity of gliding motility. Growth under low-nutrient conditions significantly increased expression of $s p r A$ in $\mathrm{Rz}$ and $\mathrm{R}$ types and the expression of $\operatorname{sprF}$ in the $\mathrm{R}$ type. In $F$. johnsoniae, SprA has been identified as a cell surface protein, and it has been hypothesized that it serves as a link between surface adhesins and gliding motor (Nelson et al., 2007). In that sense, increased production of SprA under low nutrient levels seems reasonable. Previously, it has been found that F. psychrophilum GldN expression increases in vivo and in iron-limited media (LaFrentz et al., 2009). Indeed, low-nutrient conditions induce motility in F. psychrophilum and Vibrio parahaemolyticus (McCarter, 1999; Perez-Pascual et al., 2009), whereas Salmonella enterica serovar Typhimurium and Escherichia coli, which express swarming motility on solid surfaces, act conversely (Harshey and Matsuyama, 1994; Toguchi et al., 2000). Combined with the observed phenotypic changes in colony spreading and gliding motility, our findings indicate that environmental nutrients may rather regulate the activity of gliding motility machinery, than the abundance of its components. While qPCR measures the quantity of a present mRNA of a target gene (Wong and Medrano, 2005), bacterial transcripts of secreted proteins may experience post-transcriptional and post-translational processing steps prior to transportation through the cell membranes. Consequently, failure in any of these processes may lead to unsuccessful protein translocation and may further alter the constitution of cell surface. Therefore, malfunctions in the T9SS may disrupt secretion and result in accumulation of secreted products in the cytoplasm or the periplasmic space (Sato et al., 2005; Shrivastava et al., 2013). It is also possible that gliding motilityrelated genes may be regulated via more complex pathways. In P. gingivalis, PorX and PorY putatively form a two-component signal transduction system that regulates the expression of a subset of T9SS genes, including porT, sov, porK, porL, porM, and porN (Sato et al., 2010), that correspond to sprT, sprA, gldK, gldL, gldM, and gldN in F. columnare, respectively. The gene sequences of $F$. columnare por $X$ and por $Y$ orthologs were found to be identical in different colony types, which implies that the observed gene expression differences are not a result of a mutation in these genes. Hence, the role of PorX and PorY or other regulatory mechanisms that would direct gliding motility or T9SS activity remain to be studied in more detail. For example, preparing por $X$ and por $Y$ null mutants and exploring the effect on gene expression could make an important contribution to the understanding of gliding motility and its regulation. In addition, transcriptome analysis of different strains and their colony types could provide insight into gene expression under different nutrient conditions and help to build a more comprehensive perspective on factors that are associated with colony spreading and gliding motility.

All the colony types showed proteolytic activity on highand low-nutrient milk agar, indicating that colony spreading is not associated with secretion in this $F$. columnare strain. Previous studies have demonstrated that similarly to disruption of gliding motility, mutations in the gliding motility genes affect F. johnsoniae proteinase secretion (Sato et al., 2010). Therefore, our results indicate that the genes related to gliding motility and T9SS in the studied strain B067 are intact. Furthermore, no considerable differences in proteolytic activity were detected on low- and high-nutrient milk agar, though in some cases, low nutrient concentration has been shown to decrease protease activity (Newton et al., 1997). The ECP profiles of Rz, R, and S types grown in low and high nutrient conditions did not differ remarkably from each other, except for a $\sim 13 \mathrm{kDa}$ protein band detected in ECP, which was present only in the Rz type. This protein has previously been connected to the virulent colony type (Laanto et al., 2014), but its role in pathogenicity is unknown. However, it should be noted that ECP profiles were isolated from bacteria grown in liquid media, and therefore, their ECP profiles may not fully correspond to the profiles obtained from bacteria 
grown on an agar plate (and which would express gliding motility more vigorously).

To conclude, environmental nutrients are important regulators of $F$. columnare gliding motility and the expression of associated genes. Despite the mounting data on Flavobacterium gliding motility and T9SS, the knowledge of their regulatory pathways is limited, and how environmental cues contribute to the regulation of these signaling pathways in $F$. columnare remains to be determined. Therefore, the possibility cannot be ruled out that differentially spreading morphotypes of F. columnare are caused by factors that are yet to be identified. Understanding the differences between spreading and nonspreading morphotypes may help to disentangle factors related to gliding motility and virulence in $F$. columnare.

\section{MATERIAL AND METHODS}

\section{Bacterial Strains and Growth Conditions}

In all experiments in this study, we used three different colony types (rhizoid [Rz], rough [R] and soft [S]) of F. columnare strain B067 (Laanto et al., 2011). The bacterial strain was originally isolated from a trout that was killed during a columnaris disease outbreak at Finnish fish farm (Laanto et al., 2011). The R colony type was obtained after exposing the original $\mathrm{Rz}$ isolate to bacteriophages (Laanto et al., 2012). The S type appeared spontaneously during laboratory culture of the $\mathrm{Rz}$ type (Laanto et al., 2014).

Bacterial stocks were stored at $-80^{\circ} \mathrm{C}$ in $10 \%$ fetal calf serum and $10 \%$ glycerol and revived from the freezer in fresh modified Shieh medium according to Song et al. (1988), which is referred to as Shieh medium in this study and is used as a base of nutrient-modified media. In nutrient-modified media $(0.5 \mathrm{x}$ or $2 \mathrm{x}$ Shieh), all the ingredients were either halved or doubled. In $0.5 \mathrm{xN}$ and $2 \mathrm{xN}$ Shieh media, only the concentration of peptone and yeast extract were halved or doubled, respectively (for detailed compositions of the media, see Penttinen et al., 2016). After revival from the freezer, liquid bacterial cultures were cultivated at $\mathrm{RT} / 26^{\circ} \mathrm{C}$, with agitation of $115 / 150 \mathrm{rpm}$ for 24-48 h to obtain dense cultures. Cultures were refreshed with fresh $1 \mathrm{x}$ Shieh medium, and cultivation was continued for 16-24 h. For plate cultures, dense liquid culture was streaked on a Shieh agar plate, which was incubated at RT for 2 days.

\section{Colony Morphology, Growth, and Biofilm Formation in Different Nutrient Conditions}

Liquid bacterial cultures of $\mathrm{Rz}, \mathrm{R}$, and $\mathrm{S}$ grown in $1 \mathrm{x}$ Shieh were streaked on $0.5 \mathrm{xN}, 1 \mathrm{x}$, and $2 \mathrm{xN}$ Shieh plates. Plates were incubated for 2 days at RT, after which the colony morphology was determined.

In order to evaluate the bacterial viability in different nutrient concentrations, $1.18 \times 10^{7}-1.28 \times 10^{7}$ colony forming units of B067 Rz, R, and $S$ in a total volume of $400 \mu \mathrm{l}$ containing $0.5 \mathrm{xN}, 1 \mathrm{x}$, or $2 \mathrm{xN}$ Shieh $(N=8)$ was cultivated on
Honeycomb $2^{\circledR}$ microplate (Growth Curves Ltd.) in a Bioscreen $\mathrm{C}^{\mathrm{TM}}$ spectrophotometer (Growth Curves Ltd.) at $26^{\circ} \mathrm{C}$. The absorbance $(600 \mathrm{~nm})$ was measured every $5 \mathrm{~min}$ for $65 \mathrm{~h}$. The viability was estimated as the maximum absorbance recorded during the cultivation.

The biofilm formation capacity under various nutrient conditions was determined by cultivating $1.7 \times 10^{6}-1.83 \times 10^{6}$ colony forming units of B067 Rz, R, and S in a total volume of $100 \mu \mathrm{l}$ in $0.5 \mathrm{xN}$ and $2 \mathrm{xN}$ Shieh media on a Maxisorp plate. After a 44-h -incubation at RT, the emptied wells were rinsed twice with $200 \mu \mathrm{l}$ of phosphate buffer solution (PBS). The biofilm-forming bacteria were stained with $125 \mu \mathrm{l}$ of $0.1 \%$ crystal violet solution for $10 \mathrm{~min}$ and rinsed three times with $200 \mu \mathrm{l}$ of PBS and the plate was dried at RT overnight. To solubilize the crystal violet, $125 \mu \mathrm{l}$ of $96 \%$ ethanol was added. Finally, $100 \mu \mathrm{l}$ of the solution was transferred to a fresh microplate, and absorbance was determined at the wavelength of $595 \mathrm{~nm}$ with a Multiskan FC spectrophotometer (Thermo Scientific).

\section{Imaging Bacterial Cell Movements}

Flavobacterium columnare B067 Rz cells were scratched from $0.5 \mathrm{xN}$ and $2 \mathrm{xN}$ Shieh agar plates and suspended in $0.5 \mathrm{xN}$ and $2 \mathrm{xN}$ Shieh liquid media, respectively. The cell suspension was pipetted and imaged on an eight-chambered ibidi ${ }^{\circledR}$ ibiTreat $\mu$-Slide (ibidi $\mathrm{GmbH}$ ) covered with CID lid for $\mu$-dishes (ibidi $\mathrm{GmbH})$. The bacterial cells were imaged with a Nikon AR1 laser scanning confocal microscope using a $488 \mathrm{~nm}$ Argon laser and CFI Apo VC 60x water immersion objective (numerical aperture 1.2).

In order to image the spreading behavior of the different colony types, 3-5 $\mu$ l of overnight culture of $F$. columnare B067 Rz, R, or $\mathrm{S}$ was pipetted onto an eight-chambered ibidi $^{\circledR}$ ibiTreat $\mu$-Slide (ibidi $\mathrm{GmbH}$ ) between the bottom of the chamber and a $0.5 \mathrm{xN}, 1 \mathrm{x}$, or $2 \mathrm{xN}$ Shieh agar layer. The bacteria were cultivated overnight at RT, after which the motility on the edge of the spreading colony was imaged as described above. In order to make slow bacterial movements detectable to the human eye, the videos were sped up as follows: Supplementary Videos 1-8: 4×; Supplementary Video 9: $1,800 \times$.

\section{Preparation of the Samples for Gene Expression Analysis}

Several dilutions (with Shieh media) were made from liquid bacterial cultures, which were then spread on $0.5 \mathrm{x}$ and $2 \mathrm{x}$ Shieh agar plates in order to obtain plates with separate colonies and on which the colony types were recognizable. Plate cultures were incubated at RT for 2 days, after which each plate was inspected to ensure it contained only the appropriate colony type. By diluting the bacterial cultures, close to round-shaped colonies were observed and their size was measured. A colony was considered to be the area covered with bacterial cells, including both the denser area in the middle of the colony (if present) and the more transparent area around it. Following the manufacturer's instructions, the bacterial colonies were suspended in RNA 
Protect $^{\mathrm{TM}}$ Bacteria Reagent (QIAGEN), which protects RNA from degradation. Total RNA was extracted from Rz, R, and S colonies grown on $0.5 \mathrm{x}$ and $2 \mathrm{x}$ Shieh agar plate cultures with an RNeasy ${ }^{\circledR}$ Mini Kit (QIAGEN). If there was any remaining genomic DNA, DNAse treatment with DNA-free ${ }^{\mathrm{TM}}$ (Ambion by Life Technologies) was carried out. RNA quality was verified by running the samples on an Agilent RNA 6000 Nano Chip (Agilent Technologies) in an Agilent 2100 Bioanalyzer (Agilent Technologies) and determining the RNA integrity number (RIN) for each sample. Only qualified samples (RIN above 8.7) proceeded to cDNA synthesis which was performed immediately after RNA validation. RNA was reverse-transcribed into cDNA in triplicate reactions with iScript ${ }^{\mathrm{TM}} \mathrm{cDNA}$ Synthesis Kit (Bio-Rad) according to the manufacturer's instructions. cDNA reactions with a volume of $20 \mu \mathrm{l}$ contained $1 \mathrm{x}$ iScript ${ }^{\mathrm{TM}}$ reaction mix, $1 \mu \mathrm{liScript}{ }^{\mathrm{TM}}$ reverse transcriptase, and $40 \mathrm{ng}$ of template RNA. Replicate reactions were pooled and used as a template in qPCR.

\section{RT-qPCR}

Each $20 \mu \mathrm{l}$ qPCR reaction, run in triplicates, contained $40 \mathrm{ng}$ (gapdh, glyA, gldG, gldH, gldL and, sprB) or $80 \mathrm{ng}$ (sprA, sprE, $s p r F, s p r T$ and por $V$ ) of cDNA template, $0.5 \mu \mathrm{M}$ of both forward and reverse primers and $1 \mathrm{X} \mathrm{iQ}^{\mathrm{TM}}$ SYBR Green Supermix (Bio$\mathrm{Rad})$ that contained iTaq DNA polymerase $(25 \mathrm{U} / \mathrm{ml})$. qPCR reactions conditions were as follows: $95^{\circ} \mathrm{C}$ for $3 \mathrm{~min}$, followed by 40 cycles of $95^{\circ} \mathrm{C}$ for $10 \mathrm{~s}, \mathrm{Tm}{ }^{\circ} \mathrm{C}$ for $20 \mathrm{~s}$ and $72^{\circ} \mathrm{C}$ for $20 \mathrm{~s}$, [melting temperature (Tm) was chosen according to the primer pair (Table 3)]. CFX96 ${ }^{\mathrm{TM}}$ Real-Time System C1000 ${ }^{\mathrm{TM}}$ and $\mathrm{C} 1000^{\mathrm{TM}}$ Touch Thermal Cyclers (Bio-Rad) were used in qPCR plate runs on 96-well Hard-Shell ${ }^{\circledR}$ PCR plates (Bio-Rad). On each plate, two interplate calibrator samples in triplicates were run to normalize interplate variation.

Primer-BLAST ${ }^{1}$ was used to design a primer pair for each target gene. Primers used in this study are presented in Table 3. The specific binding of each primer pair was tested by checking the amplicon length on agarose gel and with melt curve produced by CFX Manager ${ }^{\mathrm{TM}}$ Software v3.0. glyA and gapdh have been qualified as valid and stably expressed in each $F$. columnare colony type in various nutrient conditions (Penttinen et al., 2016). They were, thus, used as reference genes to normalize the gene expressions of gliding motility-associated genes. $M$-value (Vandesompele et al., 2002), which indicates gene expression stability, was measured for the current dataset for reference genes glyA and gapdh using CFX Manager version 3.0 (Bio-Rad).

\section{Relative Quantities}

For the following data prehandling, GenEx version 6.0 (MultiD Analyses) was utilized. Any missing quantification cycle (Cq) value was replaced with the average Cq of its two qPCR replicates. IPC samples run on each plate were used to minimize variation between different plate runs. Efficiency for each primer pair was calculated from a standard curve (with CFX Manager version 3.0) and Cq values were corrected with the efficiency within each gene. The averaged $\mathrm{Cq}$ values were normalized with reference

${ }^{1}$ http://www.ncbi.nlm.nih.gov/tools/primer-blast/ genes and transformed into relative gene expression with GenEx version 6.0 (MultiD Analyses).

\section{Statistical Analyses}

The effect of colony type and nutrient level on gliding motility gene expression was tested with ANOVA. Post hoc tests were Bonferroni-corrected. Data for sprA, sprE, and gldG were log-transformed to fulfill the assumption of normality and homoscedasticity. Statistical analyses were performed with IBM ${ }^{\circledR}$ SPSS ${ }^{\circledR}$ Statistics 22 (IBM Corporation), except for gldL, which could not be transformed to fulfill the assumption of ANOVA and was, thus, analyzed by ARTtool package in R (version 3.1.3) (Wobbrock et al., 2011). Pairwise comparisons were not performed for gldL.

\section{DNA Sequencing of Gliding Motility Genes in Different Colony Types}

Genomic DNA of F. columnare strain B067 colony types Rz, $\mathrm{R}$ and $\mathrm{S}$ was extracted from bacterial liquid cultures grown overnight in 1x Shieh medium at RT (115 rpm) using a GeneJET Genomic DNA Purification Kit (Thermo Scientific). The genes related to gliding motility, T9SS or their regulation ( $g l d H, s p r A$, sprE, sprT, and porV), genomic regions spanning sprCDBF, gldFG and gldKLMN as well as partners of a putative two-component system, por $X$ and por $Y$, were first amplified with PCR using genomic DNA of B067 type Rz, R or S as a template. The $20 \mu \mathrm{l}$ reactions were performed using Phusion Flash HighFidelity PCR Master Mix (Thermo Fisher Scientific), with primer concentrations of $0.5 \mu \mathrm{M}$ and a template amount of $1-10 \mathrm{ng}$ per reaction. The PCR protocol described by the manufacturer was followed, taking into account the differences in primer melting temperatures and PCR product sizes.

The organization of the genes studied in RT-qPCR assay within operons was predicted with DOOR2 (Dam et al., 2007; Mao et al., 2009) according to the genome sequence of F. columnare ATCC 49512. The genomic region upstream of the predicted operon was assumed to contain the appropriate promoter region. The upstream regions of operons gldFG, gldKLMN, and sprCDBF, those operons comprising genes gld $H$, $s p r A$, or por $V$ as well as the upstream region of the gene $\operatorname{sprE}$ (which was predicted to be expressed alone) were sequenced in B067 Rz, R, and S types.

Prior to sequencing the PCR products were purified using QIAGEN's QIAquick PCR Purification Kit. Primers for the sequencing reactions were designed in 500 bp intervals using VectorNTI version 11.5.1 (Invitrogen), utilizing our shotgun sequencing results as a template. A BigDye Terminator v3.1 Cycle Sequencing Kit (Applied Biosystems) was used for sequencing the DNA fragments using the Sanger sequencing technique with an automated sequencing instrument 3130xl Genetic Analyzer (Applied Biosystems). The identity of each base was determined with at least two good quality reads. Basecalling was done using Sequence Analysis 6 (Applied Biosystems). Gene sequence assembly and the alignment of homologous sequences of different colony types were performed with Geneious 8.1.5 (Biomatters Ltd.). The assembled gene and 
regulative region sequences of $\mathrm{Rz}, \mathrm{R}$, and $\mathrm{S}$ colony types are found in GenBank (accession number in brackets): gldFG (MF278296), the upstream region of operon comprising gldH (MF278297), gldH (MF278298), gldKLMN (MF278299), the upstream region of operon comprising sprA (MF278305), sprA (MF278306), sprCD (MF278307), sprE (MF278308), sprF (MF278309), sprT (MF278300), the upstream region of operon comprising porV (MF278301), porV (MF278302), porX (MF278303), and porY (MF278304).

\section{Protease Activity and ECP Production in Different Nutrient Concentrations}

To study the effect of nutrient level on proteolytic activity, B067 colony types $\mathrm{Rz}, \mathrm{R}$, and $\mathrm{S}$ were cultivated in $0.5 \mathrm{xN}$ and $2 \mathrm{xN}$ Shieh media and $10 \mu \mathrm{l}$ of bacterial culture (containing $1.4 \times 10^{6}$ CFUs $\pm 4 \times 10^{4}$ SE on average) were spotted, respectively, on $0.5 \mathrm{xN}$ or $2 \mathrm{xN}$ Shieh agar plates containing $1.5 \%$ skim milk (Merck). Plates were incubated for 2 days at RT, after which the clear zone (indicating proteinase production) around the bacterial growth was detected.

Extracellularly secreted product samples were prepared as follows: $8 \mathrm{ml}$ from $F$. columnare $\mathrm{Rz}, \mathrm{R}$, and $\mathrm{S}$ liquid cultures were added to $100 \mathrm{ml}$ of fresh $0.5 \mathrm{xN}$ and $2 \mathrm{xN}$ Shieh media. The cultures were grown for $19 \mathrm{~h}$. One hundred milliliters of dense bacterial culture was centrifuged at $4^{\circ} \mathrm{C}(4,500 \mathrm{rpm}, 15 \mathrm{~min})$. The supernatant was first filtered through a $0.45 \mu \mathrm{m}$ Supor ${ }^{\circledR}$ membrane (Pall Corporation) and then concentrated with $10 \mathrm{~K}$ Amicon Ultra-15 Centrifugal Filter Units (Merck Millipore) at $4^{\circ} \mathrm{C}$ to final volume of $2-3 \mathrm{ml}$. ECP samples were divided into $500 \mu \mathrm{l}$ aliquots and stored at $-20^{\circ} \mathrm{C}$. Protein concentration of the ECP samples was determined using the Bradford method (Bradford, 1976) against a standard curve made with known amounts of bovine serum albumin. Fifty micrograms of each ECP sample (except $150 \mu \mathrm{g}$ of Rz grown in $2 \mathrm{xN}$ Shieh) was loaded onto

\section{REFERENCES}

Agarwal, S., Hunnicutt, D. W., and McBride, M. J. (1997). Cloning and characterization of the Flavobacterium johnsoniae (Cytophaga johnsonae) gliding motility gene, gldA. Proc. Natl. Acad. Sci. U.S.A. 94, 12139-12144. doi: 10.1073/pnas.94.22.12139

Alvarez, B., Secades, P., Prieto, M., McBride, M. J., and Guijarro, J. A. (2006). A mutation in Flavobacterium psychrophilum tlpB inhibits gliding motility and induces biofilm formation. Appl. Environ. Microbiol. 72, 4044-4053. doi: 10.1128/AEM.00128-06

Bradford, M. M. (1976). A rapid and sensitive method for the quantitation of microgram quantities of protein utilizing the principle of protein-dye binding. Anal. Biochem. 72, 248-254. doi: 10.1016/0003-2697(76)90527-3

Braun, T. F., and McBride, M. J. (2005). Flavobacterium johnsoniae GldJ is a lipoprotein that is required for gliding motility. J. Bacteriol. 187, 2628-2637. doi: 10.1128/JB.187.8.2628-2637.2005

Castillo, D., Christiansen, R. H., Dalsgaard, I., Madsen, L., and Middelboe, M. (2015). Bacteriophage resistance mechanisms in the fish pathogen Flavobacterium psychrophilum: linking genomic mutations to changes in bacterial virulence factors. Appl. Environ. Microbiol. 81, 1157-1167. doi: 10.1128/AEM.03699-14

Dam, P., Olman, V., Harris, K., Su, Z., and Xu, Y. (2007). Operon prediction using both genome-specific and general genomic information. Nucleic Acids Res. 35, 288-298. doi: 10.1093/nar/gkl1018
$14 \%$ Tricine-SDS-PAGE gel. The gel was run for $24 \mathrm{~h}$ at $90 \mathrm{~V} / 30$ $\mathrm{mA}$ and stained with Coomassie Brilliant Blue solution.

\section{AUTHOR CONTRIBUTIONS}

$\mathrm{RP}$ and L-RS designed the study. RP and $\mathrm{VH}$ conducted the laboratory experiments. RP, L-RS, and VH wrote the manuscript.

\section{FUNDING}

This work has been funded by grants from Academy of Finland for the Centre of Excellence in Biological Interactions 2012-2017 (\#252411) and for L-RS (\#266879, \#304615), the Maj and Tor Nessling Foundation, Jane and Aatos Erkko Foundation and the Doctoral Program in Biological and Environmental Science of University of Jyväskylä.

\section{ACKNOWLEDGMENTS}

The authors would like to thank Professor Mark McBride for his valuable advice and expertise concerning flavobacterial gliding motility. Dr. Hanna Kinnula, Dr. Elina Laanto, and Mr. Juha Meriläinen are acknowledged for assistance in the laboratory and Mr. Petri Papponen and Mr. Visa Ruokolainen for technical support, in memory of Professor Jaana Bamford.

\section{SUPPLEMENTARY MATERIAL}

The Supplementary Material for this article can be found online at: https://www.frontiersin.org/articles/10.3389/fmicb. 2018.00525/full\#supplementary-material

Declercq, A. M., Haesebrouck, F., Van den Broeck, W., Bossier, P., and Decostere, A. (2013). Columnaris disease in fish: a review with emphasis on bacterium-host interactions. Vet. Res. 44:27. doi: 10.1186/1297-9716-44-27

Dumpala, P. R., Gulsoy, N., Lawrence, M. L., and Karsi, A. (2010). Proteomic analysis of the fish pathogen Flavobacterium columnare. Proteome Sci. 8:26. doi: 10.1186/1477-5956-8-26

Fabianek, R., Hennecke, H., and Thony-Meyer, L. (2000). Periplasmic protein thiol: disulfide oxidoreductases of Escherichia coli. FEMS Microbiol. Rev. 24, 303-316. doi: 10.1016/S0168-6445(00)00028-0

Garrett, T. R., Bhakoo, M., and Zhang, Z. (2008). Bacterial adhesion and biofilms on surfaces. Prog. Nat. Sci. 18, 1049-1056. doi: 10.1016/j.pnsc.2008.04.001

Haiko, J., and Westerlund-Wikstrom, B. (2013). The role of the bacterial flagellum in adhesion and virulence. Biology 2, 1242-1267. doi: 10.3390/biology2041242

Harshey, R. M., and Matsuyama, T. (1994). Dimorphic transition in Escherichia coli and Salmonella typhimurium: surface-induced differentiation into hyperflagellate swarmer cells. Proc. Natl. Acad. Sci. U.S.A. 91, 8631-8635. doi: 10.1073/pnas.91.18.8631

Hunnicutt, D. W., Kempf, M. J., and McBride, M. J. (2002). Mutations in Flavobacterium johnsoniae gldF and gld $G$ disrupt gliding motility and interfere with membrane localization of GldA. J. Bacteriol. 184, 2370-2378. doi: 10.1128/ JB.184.9.2370-2378.2002

Hunnicutt, D. W., and McBride, M. J. (2000). Cloning and characterization of the Flavobacterium johnsoniae gliding-motility genes gldB and gldC. J. Bacteriol. 182, 911-918. doi: 10.1128/JB.182.4.911-918.2000 
Hunnicutt, D. W., and McBride, M. J. (2001). Cloning and characterization of the Flavobacterium johnsoniae gliding motility genes gldD and gldE. J. Bacteriol. 183, 4167-4175. doi: 10.1128/JB.183.14.4167-4175.2001

Josenhans, C., and Suerbaum, S. (2002). The role of motility as a virulence factor in bacteria. Int. J. Med. Microbiol. 291, 605-614. doi: 10.1078/1438-422100173

Kharade, S. S., and McBride, M. J. (2015). Flavobacterium johnsoniae PorV is required for secretion of a subset of proteins targeted to the type IX secretion system. J. Bacteriol. 197, 147-158. doi: 10.1128/JB.02085-14

Kinnula, H., Mappes, J., Valkonen, J. K., Pulkkinen, K., and Sundberg, L. (2017). Higher resource level promotes virulence in an environmentally transmitted bacterial fish pathogen. Evol. Appl. 10, 462-470. doi: 10.1111/eva. 12466

Klesius, P. H., Pridgeon, J. W., and Aksoy, M. (2010). Chemotactic factors of Flavobacterium columnare to skin mucus of healthy channel catfish (Ictalurus punctatus). FEMS Microbiol. Lett. 310, 145-151. doi: 10.1111/j.1574-6968.2010. 02060.x

Kunttu, H. M., Jokinen, E. I., Valtonen, E. T., and Sundberg, L. R. (2011). Virulent and nonvirulent Flavobacterium columnare colony morphologies: characterization of chondroitin AC lyase activity and adhesion to polystyrene. J. Appl. Microbiol. 111, 1319-1326. doi: 10.1111/j.1365-2672.2011. 05149.x

Kunttu, H. M., Suomalainen, L. R., Jokinen, E. I., and Valtonen, E. T. (2009). Flavobacterium columnare colony types: connection to adhesion and virulence? Microb. Pathog. 46, 21-27. doi: 10.1016/j.micpath.2008.10.001

Laanto, E., Bamford, J. K. H., Laakso, J., and Sundberg, L. (2012). Phage-driven loss of virulence in a fish pathogenic bacterium. PLoS One 7:e53157. doi: 10.1371/ journal.pone. 0053157

Laanto, E., Penttinen, R. K., Bamford, J. K. H., and Sundberg, L. (2014). Comparing the different morphotypes of a fish pathogen - implications for key virulence factors in Flavobacterium columnare. BMC Microbiol. 14:170. doi: 10.1186/ 1471-2180-14-170

Laanto, E., Sundberg, L. R., and Bamford, J. K. (2011). Phage specificity of the freshwater fish pathogen Flavobacterium columnare. Appl. Environ. Microbiol. 77, 7868-7872. doi: 10.1128/AEM.05574-11

LaFrentz, B. R., LaPatra, S. E., Call, D. R., Wiens, G. D., and Cain, K. D. (2009). Proteomic analysis of Flavobacterium psychrophilum cultured in vivo and in iron-limited media. Dis. Aquat. Organ. 87, 171-182. doi: 10.3354/dao 02122

Li, N., Zhu, Y., LaFrentz, B. R., Evenhuis, J. P., Hunnicutt, D. W., Conrad, R. A., et al. (2017). The type IX secretion system is required for virulence of the fish pathogen Flavobacterium columnare. Appl. Environ. Microbiol. 83:e1769-17. doi: 10.1128/AEM.01769-17

Mao, F., Dam, P., Chou, J., Olman, V., and Xu, Y. (2009). DOOR: a database for prokaryotic operons. Nucleic Acids Res. 37, D459-D463. doi: 10.1093/nar/ gkn757

McBride, M. J., and Braun, T. F. (2004). GldI is a lipoprotein that is required for Flavobacterium johnsoniae gliding motility and chitin utilization. J. Bacteriol. 186, 2295-2302. doi: 10.1128/JB.186.8.2295-2302.2004

McBride, M. J., Braun, T. F., and Brust, J. L. (2003). Flavobacterium johnsoniae GldH is a lipoprotein that is required for gliding motility and chitin utilization. J. Bacteriol. 185, 6648-6657. doi: 10.1128/JB.185.22.6648-6657.2003

McBride, M. J., and Nakane, D. (2015). Flavobacterium gliding motility and the type IX secretion system. Curr. Opin. Microbiol. 28, 72-77. doi: 10.1016/j.mib. 2015.07.016

McBride, M. J., and Zhu, Y. (2013). Gliding motility and Por secretion system genes are widespread among members of the phylum Bacteroidetes. J. Bacteriol. 195, 270-278. doi: 10.1128/JB.01962-12

McCarter, L. (1999). The multiple identities of Vibrio parahaemolyticus. J. Mol. Microbiol. Biotechnol. 1, 51-57.

McGee, D. J., Coker, C., Testerman, T. L., Harro, J. M., Gibson, S. V., and Mobley, H. L. (2002). The Helicobacter pylori flbA flagellar biosynthesis and regulatory gene is required for motility and virulence and modulates urease of $H$. pylori and Proteus mirabilis. J. Med. Microbiol. 51, 958-970. doi: 10.1099/0022-131751-11-958

Nadell, C. D., Drescher, K., and Foster, K. R. (2016). Spatial structure, cooperation and competition in biofilms. Nat. Rev. Microbiol. 14, 589-600. doi: 10.1038/ nrmicro.2016.84
Nelson, S. S., Bollampalli, S., and McBride, M. J. (2008). SprB is a cell surface component of the Flavobacterium johnsoniae gliding motility machinery. J. Bacteriol. 190, 2851-2857. doi: 10.1128/JB.01904-07

Nelson, S. S., Glocka, P. P., Agarwal, S., Grimm, D. P., and McBride, M. J. (2007). Flavobacterium johnsoniae SprA is a cell surface protein involved in gliding motility. J. Bacteriol. 189, 7145-7150. doi: 10.1128/JB.00892-07

Nelson, S. S., and McBride, M. J. (2006). Mutations in Flavobacterium johnsoniae $s e c D F$ result in defects in gliding motility and chitin utilization. J. Bacteriol. 188, 348-351. doi: 10.1128/JB.188.1.348-351.2006

Newton, J. C., Wood, T. M., and Hartley, M. M. (1997). Isolation and partial characterization of extracellular proteases produced by isolates of Flavobacterium columnare derived from channel catfish. J. Aquat. Anim. Health 9, 75-85. doi: 10.1577/1548-866719970092.3.CO;2

Nilsen, H., Sundell, K., Duchaud, E., Nicolas, P., Dalsgaard, I., Madsen, L., et al. (2014). Multilocus sequence typing identifies epidemic clones of Flavobacterium psychrophilum in Nordic countries. Appl. Environ. Microbiol. 80, 2728-2736. doi: 10.1128/AEM.04233-13

Penttinen, R., Kinnula, H., Lipponen, A., Bamford, J. K. H., and Sundberg, L. (2016). High nutrient concentration can induce virulence factor expression and cause higher virulence in an environmentally transmitted pathogen. Microb. Ecol. 72, 955-964. doi: 10.1007/s00248-016-0781-1

Perez-Pascual, D., Menendez, A., Fernandez, L., Mendez, J., Reimundo, P., Navais, R., et al. (2009). Spreading versus biomass production by colonies of the fish pathogen Flavobacterium psychrophilum: role of the nutrient concentration. Int. Microbiol. 12, 207-214.

Rhodes, R. G., Nelson, S. S., Pochiraju, S., and McBride, M. J. (2011a). Flavobacterium johnsoniae sprB is part of an operon spanning the additional gliding motility genes $s p r C$, sprD, and $s p r F$. J. Bacteriol. 193, 599-610. doi: 10.1128/JB.01203-10

Rhodes, R. G., Samarasam, M. N., Van Groll, E. J., and McBride, M. J. (2011b). Mutations in Flavobacterium johnsoniae sprE result in defects in gliding motility and protein secretion. J. Bacteriol. 193, 5322-5327. doi: 10.1128/JB.05480-11

Rhodes, R. G., Samarasam, M. N., Shrivastava, A., van Baaren, J. M., Pochiraju, S., Bollampalli, S., et al. (2010). Flavobacterium johnsoniae gldN and gldO are partially redundant genes required for gliding motility and surface localization of SprB. J. Bacteriol. 192, 1201-1211. doi: 10.1128/JB.01495-09

Sato, K., Naito, M., Yukitake, H., Hirakawa, H., Shoji, M., McBride, M. J., et al. (2010). A protein secretion system linked to bacteroidete gliding motility and pathogenesis. Proc. Natl. Acad. Sci. U.S.A. 107, 276-281. doi: 10.1073/pnas. 0912010107

Sato, K., Sakai, E., Veith, P. D., Shoji, M., Kikuchi, Y., Yukitake, H., et al. (2005). Identification of a new membrane-associated protein that influences transport/maturation of gingipains and adhesins of Porphyromonas gingivalis. J. Biol. Chem. 280, 8668-8677. doi: 10.1074/jbc.M413544200

Shoji, M., Sato, K., Yukitake, H., Kondo, Y., Narita, Y., Kadowaki, T., et al. (2011). Por secretion system-dependent secretion and glycosylation of Porphyromonas gingivalis hemin-binding protein 35. PLoS One 6:e21372. doi: 10.1371/journal. pone. 0021372

Shrivastava, A., Johnston, J. J., van Baaren, J. M., and McBride, M. J. (2013). Flavobacterium johnsoniae GldK, GldL, GldM, and SprA are required for secretion of the cell surface gliding motility adhesins SprB and RemA. J. Bacteriol. 195, 3201-3212. doi: 10.1128/JB.00333-13

Song, Y., Fryer, J., and Rohover, J. (1988). Comparison of six media for the cultivation of Flexibacter-Columnaris. Fish Pathol. 23, 91-94. doi: 10.3147/jsfp. 23.91

Tekedar, H. C., Karsi, A., Gillaspy, A. F., Dyer, D. W., Benton, N. R., Zaitshik, J., et al. (2012). Genome sequence of the fish pathogen Flavobacterium columnare ATCC 49512. J. Bacteriol. 194, 2763-2764. doi: 10.1128/JB.00281-12

Tekedar, H. C., Karsi, A., Reddy, J. S., Nho, S. W., Kalindamar, S., and Lawrence, M. L. (2017). Comparative genomics and transcriptional analysis of Flavobacterium columnare strain ATCC 49512. Front. Microbiol. 8:588. doi: 10.3389/fmicb.2017.00588

Toguchi, A., Siano, M., Burkart, M., and Harshey, R. M. (2000). Genetics of swarming motility in Salmonella enterica serovar typhimurium: critical role for lipopolysaccharide. J. Bacteriol. 182, 6308-6321. doi: 10.1128/JB.182.22.63086321.2000

Vandesompele, J., De Preter, K., Pattyn, F., Poppe, B., Van Roy, N., De Paepe, A., et al. (2002). Accurate normalization of real-time quantitative 
RT-PCR data by geometric averaging of multiple internal control genes. Genome Biol. 3:RESEARCH0034. doi: 10.1186/gb-2002-3-7-resear ch0034

Wagner, B., Wise, D., Khoo, L., and Terhune, J. (2002). The epidemiology of bacterial diseases in food-size channel catfish. J. Aquat. Anim. Health 14, 263-272. doi: 10.1577/1548-866720020142.0.CO;2

Wobbrock, J. O., Findlater, L., Gergle, D., and Higgins, J. J. (2011). “The aligned rank transform for nonparametric factorial analyses using only ANOVA procedures," in Anonymous Proceedings of the ACM Conference on Human Factors in Computing Systems, Vancouver, BE, 143-146. doi: 10.1145/1978942. 1978963

Wong, M. L., and Medrano, J. F. (2005). Real-time PCR for mRNA quantitation. Biotechniques 39, 75-85. doi: 10.2144/05391RV01
Conflict of Interest Statement: The authors declare that the research was conducted in the absence of any commercial or financial relationships that could be construed as a potential conflict of interest.

The reviewer JW and handling Editor declared their shared affiliation.

Copyright $\odot 2018$ Penttinen, Hoikkala and Sundberg. This is an open-access article distributed under the terms of the Creative Commons Attribution License (CC BY). The use, distribution or reproduction in other forums is permitted, provided the original author(s) and the copyright owner are credited and that the original publication in this journal is cited, in accordance with accepted academic practice. No use, distribution or reproduction is permitted which does not comply with these terms. 